\title{
THE EFFECT OF JOB EMBEDDEDNESS ON ORGANIZATIONAL CITIZENSHIP BEHAVIOR The Mediating Role of Sense of Responsibility
}

\author{
B. Riwi Wijayanto \\ Gugup Kismono
}

This study examines anewattachment conceptcalled job embeddedness as antecedent of organizational citizenship behavior (OCB). Firstly, we tested hypothesis concerning positive relationship between job embeddedness and $O C B$ as predicted by Mitchell et al. (2001). Secondly, we tested hypothesis concerning the mediation effect of sense of responsibility in the relationship between job embeddedness and $O C B$.

Nurses $(N=170)$ and their immediate supervisors $(N=41)$ from five privately owned hospital in Jogjakarta participated in this study. Of 340 questionnaires distributed to the respondents, 339 were returned yielding a response rate of 99 percent. Of those returned, 300 questionnaires were available for further analyses. Nurses were asked to respond to a questionnaire of 40 items concerning perception of embeddedness and 4 item concerning sense of responsibility to their employing organization. Nurses' citizenship behavior were measured using 12 items as rated by their immediate supervisors.

The results support the hypothesis that job embeddedness correlates positively with $O C B$. However, our result failed to support the prediction of the mediating effect of employees' sense of responsibility in causal relationship between job embeddedness and $O C B$. The implications of the findings for further research on relationship between job embeddedness and $O C B$ research are discussed.

Keywords: altruism; community related sacrifice; fit to community; link to organization; job embeddedness; organizational citizenship behavior; organization related sacrifice; sense of responsibility 


\section{Introduction}

Recently, there has been a great deal of interest among researchers and practitioners on the topic of OCB. Such interests developed especially because OCB was considered critical in facilitating organizational effectiveness (Katz 1964 in Robinson and Morrison1995; Van Dyne et al. 1994; Podsakoff and MacKenzie 1994; Bolino et al. 2002). Following this argument a number of studies have been conducted to explore the antecedents of such behavior (Bateman and Organ 1983; Smith et al. 1983; Becker 1992; Bolon 1997; Shore and Wayne 1993; Settoon et al. 1996; Moorman et al. 1998; Wayne et al. 2002). Based on literature review, we found that there were at least four metaanalysis studies that have been conducted on predictors of OCB (Organ and Ryan 1995; Podsakoff et al. 1996; Podsakoff et al. 2000 in LePine et al. 2002; and LePine et al. 2002). However, even with numerous researches on OCB area, still, the development of OCB theory is relatively slow (Konovsky and Pugh 1994); especially with regard to the antecedents of OCB (Podsakoff et al. 2000 in Cardona et al. 2003). Thus, research focusing on the antecedents of OCB is still needed and this is part of our interest.

Mitchell et al. (2001) introduce a new concept called job embeddedness. Job embeddedness represents a broad constellation of forces; from job as well as community context, that might influence employee attachment to their employing organization. Those forces generated from (1) the extent to which people have links to other people or activities; both on organization and community environment, (2) the extent to which their job and communities are similar to or fit with aspects in their life spaces, and (3) individuals per- ception about cost or sacrifice if they leave their employing organization or their community. Furthermore while, Mitchell et al. (2001) also suggested that embedded individuals tend to perform more $\mathrm{OCB}$, however there are no empirical tests conducted to support this notion.

In this study, we seek to explore the role of job embeddedness (JE) on OCB. Since there have not been any researches conducted on the relationship between job embeddedness and $\mathrm{OCB}$, we first test whether there is a positive relationship between JE and OCB as predicted by Mitchell et al (2001) in a correlation study.

Next, we also propose that the causal relationship between job embeddedness and OCB will be mediated by variable reflecting employee concern or sense of responsibility to their employing organization. This prediction is based on voluntary characteristic of OCB (Smith et al. 1983); that is, such behavior is not directly related with reward to individual who perform OCB (Organ 1988; in Bolon 1997). We argue that, due to the voluntary nature of OCB, intrinsic motivator like employee personal concern or sense of responsibility to their employing organization will serve as underlying motive of embedded individual's involvement in OCB like behaviors, and thus will become potential mediator between job embeddedness and OCB.

Literatures also indicated that individuals psychological attachment to their organization (O'Reilly and Chatman 1989) and also their surrounding community; especially on-the-job community (such as group and co-worker) (Pearce and Gregersen 1991; DePasquale 1999), might foster employee's sense of responsibility. In fact, in several literatures, sense of responsibility has been considered as important motive that underlies individuals 
Wijayanto \& Kismono - The Effect of Job Embeddedness on Organizational Citizenship Behavior

involvement in some forms of extra role behavior (Morrison and Phelps 1999; Frese et al. 1996; Pearce and Gregersen 1991; DePasquale 1999). This recognition was in accordance with Pearce and Gregersen (1991) who suggested that some extra roles like behavior occurs from employee sense of responsibility to others, such as organization, individuals, and clients. Based on the above reasoning, we predict that job embeddedness will have positive effect on OCB, through the mediating role of employee's sense of responsibility to their organization.

Overall, there are two research questions that we seek to answer with this study. First, whether job embeddedness has positive relationship with OCB. Second, whether employee's sense of responsibility will mediate the effect of job embeddedness on OCB.

\section{Theoretical Background}

\section{Relationship Between Job Embeddedness and $\mathrm{OCB}$}

\section{Organizational Citizenship Behavior}

OCB refers to employee's behavior that is extra role, that promotes organizational effectiveness, and that is not explicitly recognized by an organization's reward system (Organ 1988 in Robinson and Morrison 1995). OCB is a form of Katz (1964) in Smith et al. 1983, category of employee's spontaneous behavior that goes beyond role prescription which is beneficial to organizational effectiveness.

Some researches used different terminologies in order to label employee's spontaneous behavior that goes beyond role prescription, such as: citizenship behavior (e.g. Bateman and Organ 1983), organizational citizenship behavior
(Konovsky and Organ 1996), prosocial behavior (e.g. George 1991), or contextual performance (Motowidlo and Van Scooter 1994). Though there are differences among terminologies, they possess some similarities in that they all represent behavior that is extra role, personal and voluntary in nature.

OCB is reflected in several dimensions (Greenberg and Baron 2000; LePine et al. 2002). This is in accordance with previous studies which tend to conceptualize OCB as construct comprised of several behavioral dimensions (see: Smith et al. 1983; Organ 1988 in LePine et al. 2002; Morrison 1994; Van Dyne et al. 1994; Van Scooter and Motowidlo 1996).

There are three major factors that contribute to employee's involvement in OCB. They are (1) expectation of organizational fairness, (2) employee's perception regarding in role and extra role, (3) and positive attitude toward organization (Greenberg and Baron 2000). This is consistent with previous finding suggesting that employee's positive attitude toward organization and organization's prosocial activities toward employee are important motivator in employee's OCB (e.g. Bateman and Organ 1983; Cardona and Espejo 2002; Bolon 1997; Netemeyer et al. 1997; Wayne et al. 2002; Settoon et al. 1996).

\section{Job Embeddedness}

The notion of embeddedness was previously used in sociology and economics literatures to describe the power of social structure on economic activities of individual and other social units (Uzzi 1997; Shepard et al. 1997). Baum (1992) in Shin et al. (2002), emphasized that the depth of involvement of economics actors in relational structure will determine their level of embeddedness to their social structure. 
The concept of job embeddedness represents a broad constellation of forces that might influence employee attachment to their employing organization (Mitchell et al. 2001). Mitchell et al. (2001) suggested that organization context and community in which individuals belong, generate forces that would foster individuals to become stuck with his/her environment and in turn will foster individual to remain with his/her employing organization.

Mitchell et al. (2001) classified those forces from organization and community context into six dimensions.

(1) Link to community, represents individuals' formal and informal relationships with their community. Mitchell et al. (2001) propose that a number of strands connect an employee and his or her family in social, psychological, and financial web that includes non work friends, groups, and community. The higher the number of links between the person and the web, the more she or he is bound to job and organization.

(2) Link to organization, represents individuals formal and informal relationships with other individuals in organization. Mitchell et al. (2001) also propose that as individuals have more tenure in organization, they tend to have a number of connections with other individuals (co-worker). Studies in organizational commitment have showed that commitment might develop from normative pressures arising from socialization process experienced by employee (in Meyer et al. 1993). Granovetter (1985) in Van Dyne et al. (1994) suggested that employees who have been with their employing organizations for a long time were more likely to have embedded relationship. Van Dyne et al.
(1994) supported this notion by suggesting that organizational tenure will lead to the development of ties between individuals and organization.

(3) Fit to community represents employee's perception of compatibility or comfort with her or his environment. Employees consider how well he or she fits the community and surrounding environment (Mitchell et al. 2001). Environment, and the community within it, is able to create meaning to individuals which from time to time will enhance individual's attachment to it (Vaske and Kobrin 2001: p. 17). The better the fit and the comfort with the community, the higher the likelihood that an employee will feel attached to his or her employing institution.

(4) Fit to organization represents employee's perception of compatibility or comfort with her or his organization. Employees consider how well he or she fits an organization (Mitchell et al. 2001). According to Mitchell et al. (2001), an employee considers how well his or her personal values, career goals, and plans for the future fit with the larger organization culture and the demands of his or her immediate job. Person-organization fit theory suggested that compatibility between values held by individuals and by their employing organization stimulate positive attitude toward organization and willingness to exert effort on the behalf of the organization (Chatman 1991; in Netemeyer et al. 1997; Kristof 1996). Thus, the better the fit and the comfort employee perceived with his or her organization, the higher the likelihood that an employee will feel attached professionally and personally to his or her employing institution. 
Wijayanto \& Kismono - The Effect of Job Embeddedness on Organizational Citizenship Behavior

(5) Community related sacrifice represents perceived material and psychological benefits by being member of the community that may be forfeited if one leaves a job or an organization. Leaving attractive, safe, and respectful community might become a hard decision to make (Mitchell et al. 2001) because it could cause an individual severe lost of social support and relationship with his pleasant and comfortable community (Feldman and Bolino 1998; in Pracimasanti 2004). Thus, the higher the sacrifice he or she perceived when leaving the community, the more he or she is bound to the organization.

(6) Organizational related sacrifice represents perceived material and psychological benefits by working with one's current institution that may be forfeited if one leaves a job or an organization (Mitchell et al. 2001). Feldman and Bolino (1998) in Pracimasanti 2004) suggested that individuals experienced several losses such as uncertainty about new employment, unstable income, loss of interesting projects, and also good relationship with co-worker when one leaves the job. The more severe the loss individual perceived when leaving his or her current job or organization, the more he or she is bound to the organization.

Employee's embeddedness might influence employee's subsequent behavior, such as low turn over intention as found by Mitchell et al. (2001) and Pracimasanti (2004). Furthermore, Mitchell et al. (2001) also suggested that embedded individuals tend to perform more roles beneficial for the organization, such as OCB.

\section{Relationship between Job Embeddedness and $\mathrm{OCB}$}

The first purpose of this study is to test whether there is a positive relationship between job embeddedness and OCB. To our knowledge, there have not been studies that specifically examined the relationship between job embeddedness and OCB. For this reason, we adopted previous studies on $\mathrm{OCB}$, especially those that involved organizational commitment and job satisfaction, in order to develop our theoretical basis for the first hypothesis. This decision is based on (1) previous studies which suggested that organizational commitment and job satisfaction were two important concepts that have been widely tested and recognized as important predictors of $\mathrm{OCB}$ (Organ and Ryan 1995; Greenberg and Baron 2000; Podsakoff et al. 2000; in Bolino et al. 2002); and that (2) job embeddedness has been conceptualized as a complementary construct of organizational commitment and job satisfaction, and in some aspects has similarities with those two widely researched constructs (Mitchell et al. 2001).

Previous studies on the relationship between organizational commitment and OCB have indicated that there is a positive relationship between employees' commitment to organization, or at least some dimensions of it and their involvement in OCB (see: O'Reilly and Chatman 1986; Becker 1992; Hunt and Morgan 1994; Bolon 1997; Shore and Wayne 1993; Cardona and Espejo 2002; Schappe 1998; Ackfeldt and Coote 2000). Studies also indicated that OCB was positively related with employee's satisfaction (see: Bateman and Organ 1983; Smith et al. 1983; Netemeyer et al. 1997; Van Dyne et al. 1994; Organ and Konovsky 1989; Williams and Anderson 1991; Bolon 1997; Puffer 1987). 
Based on (1) previous research suggesting the positive relationship between organizational commitment and OCB as well as job satisfaction and $\mathrm{OCB}$; and also (2) similarities between job embeddedness, organizational commitment, and job satisfaction as suggested by Mitchell et al. (2001), we expect that there is a positive relationship between job embeddedness and OCB in our study. Thus, the first hypothesis is:

Hypothesis 1: There is a positive relationship between job embeddedness and employee's citizenship behavior.

\section{The Mediating Effect of Sense of Responsibility on the Relationship between Job Embeddedness and $\mathrm{OCB}$.}

\section{The Concept of Sense of Responsibility}

Sense of responsibility refers to a psychological sense of responsibility for helping others (Pearce and Gregersen 1991). In the present study context, sense of responsibility is a form of employee's concern that is asymmetric in nature (asymmetric sense of obligation) to their employing organization. The asymmetric nature of sense of responsibility suggests that this feeling is not based on direct quid pro quo basis from the recipient but it is based on individual willingness to help others (Pearce and Gregersen 1991).

Some forms of extra role behavior may occur from employee's sense of responsibility (Pearce and Gregersen 1991). Literatures have suggested the importance of sense of responsibility in studies on extra role behavior (Pearce and Gregersen 1991; Frese et al. 1996; Morrison and Phelps 1999; DePasquale 1999). This would be an indication that $\mathrm{OCB}$, as a form of extra role behavior, may develop from employee's feeling of responsibility toward others, which, in the current study, this feeling of responsibility is directed to help the organization.

Contextual factors, such as employee's psychological attachment to their employing organization, groups, or individual, have been suggested to influence sense of responsibility. O'Reilly and Chatman(1986) suggested that employee's psychological attachment to their organization would lead to subsequent attitude such as concern to organization welfare and willingness to exert extra effort on the behalf of the organization. Moreover, literatures also indicated that relationship between employee and other individuals (co-worker) in task interdependence (Pearce and Gregersen 1991) and with other individuals in cohesive group (DePasquale 1999) might lead to the development of employee's personal responsibility, which in turn will motivate employee's involvement in extra role behavior.

The Development of Hypothesis Concerning the Role of Sense of Responsibility in Mediating the Effect of Job Embeddedness on OCB.

Our second purpose in this study is to test the role of sense of responsibility as mediator in causal relationship between job embeddedness and OCB. As in first hypothesis, in order to develop the theoretical basis for our second proposition, we adopt previous literatures on the relationship between individual's psychological attachment with organization, group, or other individuals, and the development of personal responsibility. Moreover, we also adopt literatures concerning the positive relationship between employee's sense of responsibility and their subsequent extra role behavior. Based on previous studies suggesting that individual's attachment 
Wijayanto \& Kismono - The Effect of Job Embeddedness on Organizational Citizenship Behavior

to organization (O'Reilly and Chatman 1986), group (DePasquale 1999), as well as other individuals (Pearce and Gregersen 1991) will lead to the development of employee's concern or sense of responsibility toward other; and the role of sense of responsibility in predicting employee extra role behavior (Pearce and Gregersen 1991; Frese et al. 1996; Morrison and Phelps 1999; DePasquale 1999), we predict that there is a mediating mechanism in the causal relationship between job embeddedness and OCB. The logic behind this prediction is based on Mitchell et al. (2001) notion which suggested that embedded individuals perceive themselves as being part of their surroundings (in our context, individuals are being part of their organization). This perception will lead individuals to consider organization's interest and welfare; as partner in this embedded relationship, as part of their concern or responsibility. It means that employee has an obligation to support organization in order to maintain organization's welfare. This feeling of responsibility will in turn lead to the development of employee's OCB. Thus, the second hypothesis is:

Hypothesis 2: Employee's sense of responsibility toward organization will mediate the effect ofjob embeddedness on $O C B$.

In the present study, the relationship between job embeddedness and OCB, as well as the effect job embeddedness and sense of responsibility have on OCB are analyzed in each OCB dimensions. This strategy is based on recent conceptualization of OCB as latent multidimensional construct (LePine et al. 2002), and Becker and Vance (1993) in Cardona and Espejo (2002) who suggested that in order to have a better understanding of OCB construct, research should relate different OCB dimensions with its predictors. Research model for the current study is presented in Figure 1.

Figure 1. Research Model

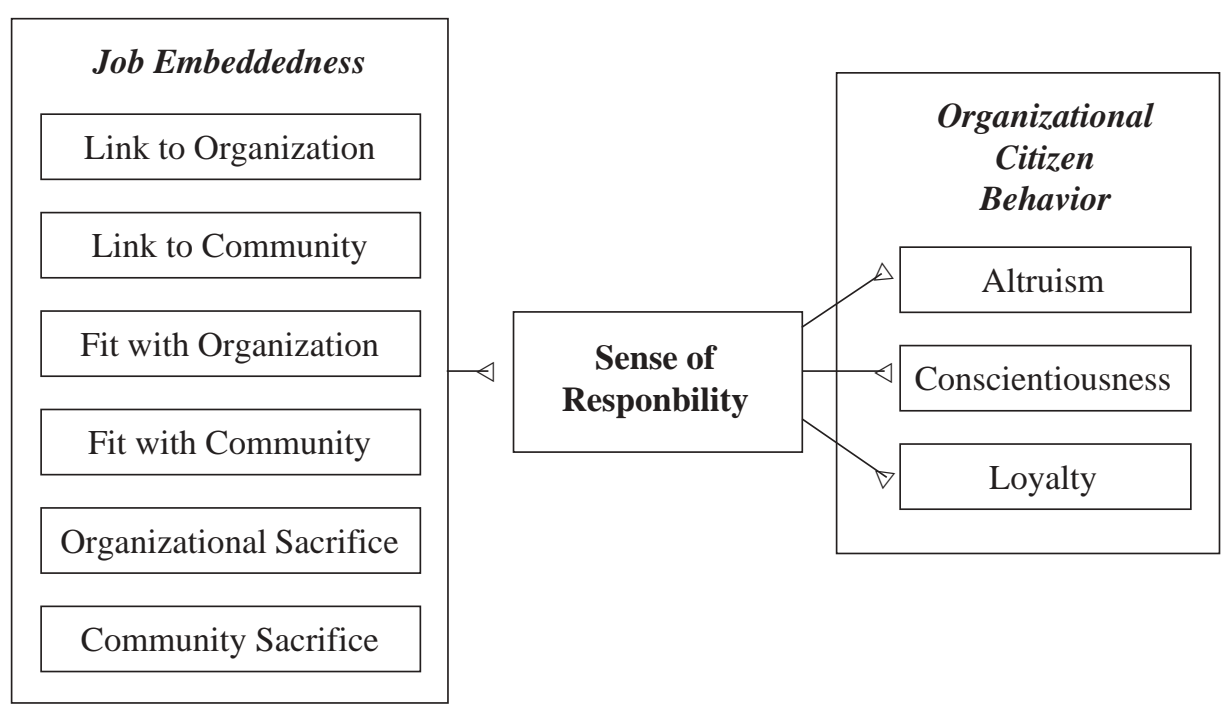




\section{Methods}

\section{Sample and Sampling Procedures}

The survey was conducted on five privately owned hospitals located in Daerah Istimewa Yogyakarta. Respondents were nurses with a minimum two years of tenure, and their immediate supervisors. 170 nurses and 41 supervisors participated in this study. Nurses were asked to give response about their perception of embeddedness, with and feeling of responsibility toward hospital where they work, while supervisors were asked to rate their subordinates' OCB. We expect that by asking supervisors to rate employee we will be able to reduce common methods bias from the use of self report measures.

We collected the data from November 2003 to December 2003. There were 170 pairs of questionnaires or 340 questionnaires distributed to the five hospitals participating in this study. From the 340 questionnaires distributed, 339 are returned, yielding 99 percent of response rate. From those returned, 169 came from nurses' responses and 170 questionnaires came from supervisors. Since responses from supervisors will be combined with responses from nurses (paired), the authors eliminate one response from supervisor that does not have its pair. The subsequent data analysis yield 300 paired questionnaires that are available for further analysis. They comprised of 150 responses from nurses $(n=150)$, and 150 from supervisors evaluation on employee OCB $(n=40)$.

Nurses comprised of 84 percent women, with the average age of 31 years old (s.d.= 7.06) and 72.7 percent of them are married. They had worked in the industry for an average 10 years (s.d. 6.56), for the hospital for an average 8.8 years (s.d.= 6.02), and in their current position for an average 7 years (s.d.= 4.90). In addition, based on information provided by human resources department in each hospital, from the final 40 supervisors involved in this study, 31 of them are women $(77.5 \%)$ with an average age of 39 years old (s.d.= 8.42).

\section{Measures}

\section{Job embeddedness}

Data Standardization for Job Embeddedness. Some of the items in link dimensions of job embeddedness have different scale from the others; i.e. marital status, spouse employment status, house ownership, tenure in nursing industry, tenure in organization, and period they have been in their current position. Before conducting further analysis for this study, we first standardized those items into $Z$ score. This process is in line with Mitchell et al. (2001) procedure.

The development of job embeddedness as aggregate. Job embeddedness is an aggregate formed from six dimensions (Mitchell et al., 2001). In order to develop the overall or aggregate measure of job embeddedness, we follow Mitchell et al. (2001) procedure by computing the mean of six dimensions of job embeddedness (mean of means).

Job embeddedness was measured using 40 items developed by Mitchell et al. (2001) for hospital employee in their study. The 40 items have already been classified into their dimensions by Mitchell et al. (2001).

(1) Fit to community was measured using five items; Likert five point scale, asking respondent perception of fit with their community.

(2) Fit to organization was measured using nine items; Likert five point scales, 
Wijayanto \& Kismono - The Effect of Job Embeddedness on Organizational Citizenship Behavior

asking respondent perception of fit with their co-worker, organizational values and culture, job, and also job responsibility given by the institution.

(3) Links to community were measured using six items. The first-three of them were categorical or dichotomous items, measuring respondent's marital status, spouse's employment status, and house ownership while the remaining three items were Likert five point scales asking respondent's family roots, proximity with their family and their relatives, and also with their close friend.

(4) Links to organization were measured using seven items. The first-three items measured tenure in nursing industry, tenure in organization, and period they have been in their current position using fill-in-the-blank responses. The remaining four items were Likert five point scales, asking respondents' link to other individuals in the hospital where they work

(5) Community related sacrifices were measured using three items, Likert five point scales, to indicate respondent's perceived sacrifice when they have to leave their current community.

(6) Organizational related sacrifices were measured using ten items, Likert five point scales. It measured respondent's perception of career, promotional opportunities, perks, benefits, and opportunity of continuing employment with current institution, that would be sacrificed if they leave their current job.

\section{Sense of Responsibility}

Respondent's psychological sense of responsibility toward others, which in our study is directed toward the organization, was measured using four items, Likert five point scales developed by Hackman and Oldham (1975) in Pearce and Gregersen (1991). Respondents were asked to indicate their feeling of responsibility or concern toward organization using respondents sense of responsibility toward tasks in their organization as proxies.

\section{Organizational citizenship behavior}

Employee's OCB was measured using altruism, conscientiousness, and loyalty dimensions previously used in Cardona and Espejo (2002). Altruism corresponded to behaviors that benefit specific individuals and, through them, contribute to organization. Altruism was measured using four item Likert seven point scales. Conscientiousness corresponded to behaviors representing respect for the rules and policies of an organization. Conscientiousness was measured using four item Likert seven point scales. Loyalty represented allegiance to an organization and promotion of its interests. It was measured using four item Likert seven point scales.

\section{Data Analysis Procedures}

\section{Validity and Reliability}

Job embeddedness is an aggregate formed from six dimensions (Mitchell et al. 2001; see Law et al. 1998). The survey instruments measure three causal indicators of the dimensions for employee's embeddedness to their employing organization (Mitchell et al. 2001; see Bollen and Lenox 1991). In a path diagram, causal arrows would go from the causal indicators (items) to the six dimensions and from the dimensions to the aggregate construct (Mitchell et al. 2001). Because of its natures, which different from common assumption in factor analysis (for detailed assumption of factor analysis, see Hair et 
Gadjah Mada International Journal of Business, September 2004, Vol. 6, No. 3

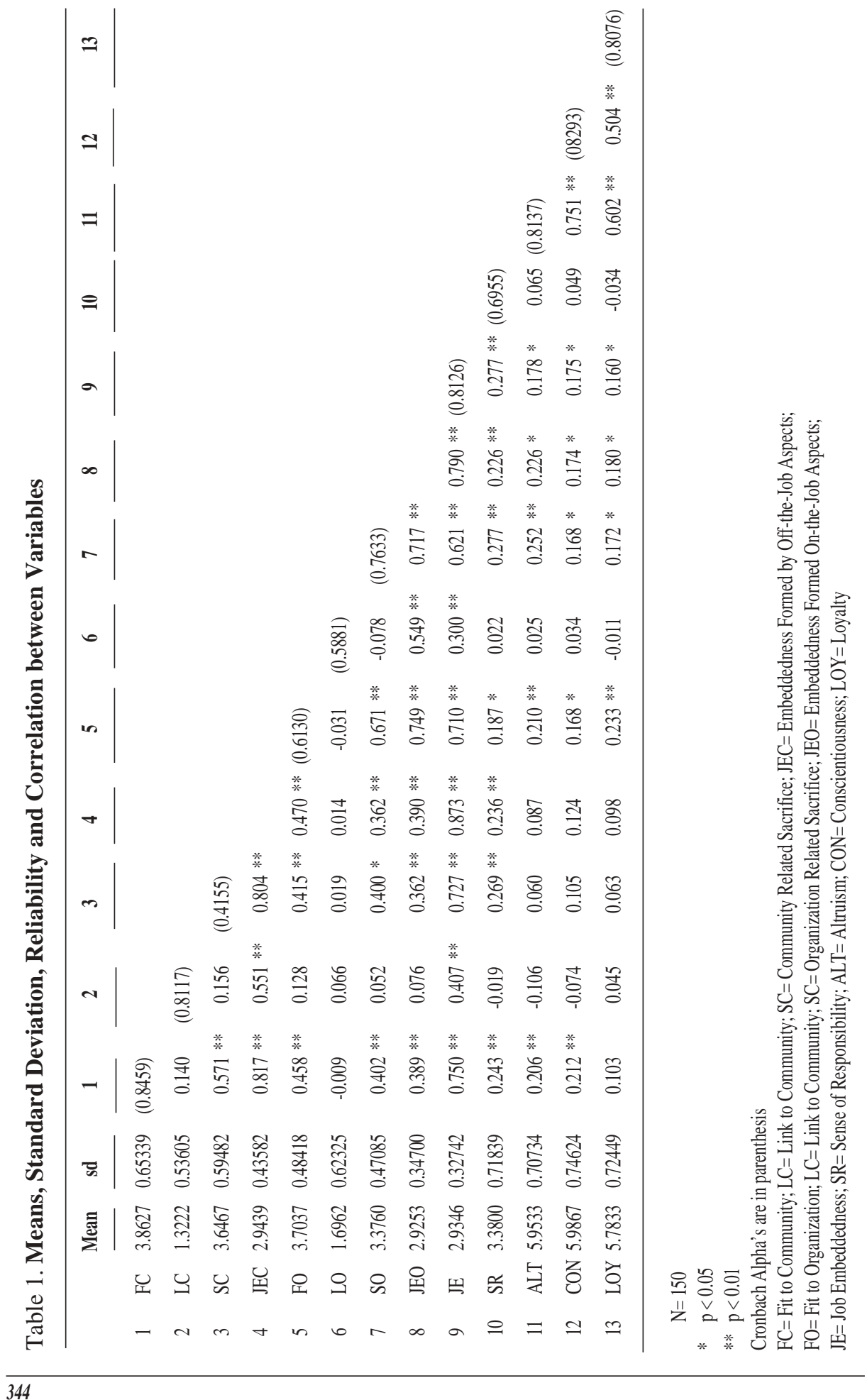


Wijayanto \& Kismono - The Effect of Job Embeddedness on Organizational Citizenship Behavior

al. 1998; Bollen and Lennox 1991), the authors decided not to conduct construct validity test using factor analysis.

In addition, because of the nature of job embeddedness, the authors decided to use different approach in conducting reliability analysis for job embeddedness. This procedure based on previous suggestion on construct that consists of causal indicators (Bolen and Lennox 1991; Chin 1998) and taxonomy of latent multidimensional constructs (Law et al. 1998). The result of reliability analysis is presented in Table 1 .

\section{Tests of Hypothesis}

Our focuses in study are to test whether there is a positive relationship between job embeddedness (as an aggregate form of it six dimensions) and OCB, and whether sense of responsibility will mediate the effect of job embeddedness on OCB. Becker and Vance (1993) in Cardona and Espejo (2002) suggested that in order to have a better understanding on the OCB construct, future research should relate different OCB dimensions with organizational commitment and job satisfaction.

LePine et al. (2002) in their metaanalysis found no significant differences in the relationship between the previously most common predictors of OCB and each dimension of OCB as well as construct of OCB as latent a whole. This finding was supported by Cardona and Espejo (2002) who found that organizational commitment has significant effect for altruism, conscientiousness, and loyalty when OCB was measured using self report method. In this study, therefore the relationship between predictors and $\mathrm{OCB}$ is examined on each OCB dimension (altruism, conscientiousness, and loyalty).

To test the first hypothesis, we conducted a correlation analysis using Pearson product-moment correlation between job embeddedness as an aggregate of its six dimensions and each dimension of OCB. The purpose of correlation analysis is to explore whether there is a positive relationship between job embeddedness and OCB since, to our knowledge, there is not any study conducted specifically on this relationship. To test the second hypothesis, we conducted a mediated regression analysis following Baron and Kenny (1986) in Kenny (2003) procedure separately on each of OCB dimensions.

\section{Analysis}

Table 1 presents the descriptive statistics of mean score, standard deviation, correlation between construct in this study. It also presents the result of reliability analysis for each variable.

Results from internal consistency reliability show that Cronbach's alpha for sense of responsibility was 0.6955 , and for each of OCB dimensions was 0.8137 (altruism), 0.8293 (conscientiousness), and 0.8076 (loyalty). Moreover, internal consistency reliability of dimensions of job embeddedness were 0.8459 for fit to community, 0.8117 for fit to organization, 0.4155 for link to community, 0.6130 for link to organization, 0.5881 for community related sacrifice, and 0.7633 for organization related sacrifice. The Cronbach's alpha for overall job embeddedness was 0.8126

From Table 1, it can also be shown that employee has a moderate level in overall embeddedness (mean $=2.9346$, s.d. $=0.32742$ ) and sense of responsibility $($ mean $=3.38$, s.d.=0.71839). Moreover, based on supervisor's evaluation on employee's extra role activities, the result presented here show that nurses in this study tend to perform OCB (altruism: mean $=5.9533$, s.d. $=0.70734$; conscien- 
Gadjah Mada International Journal of Business, September 2004, Vol. 6, No. 3

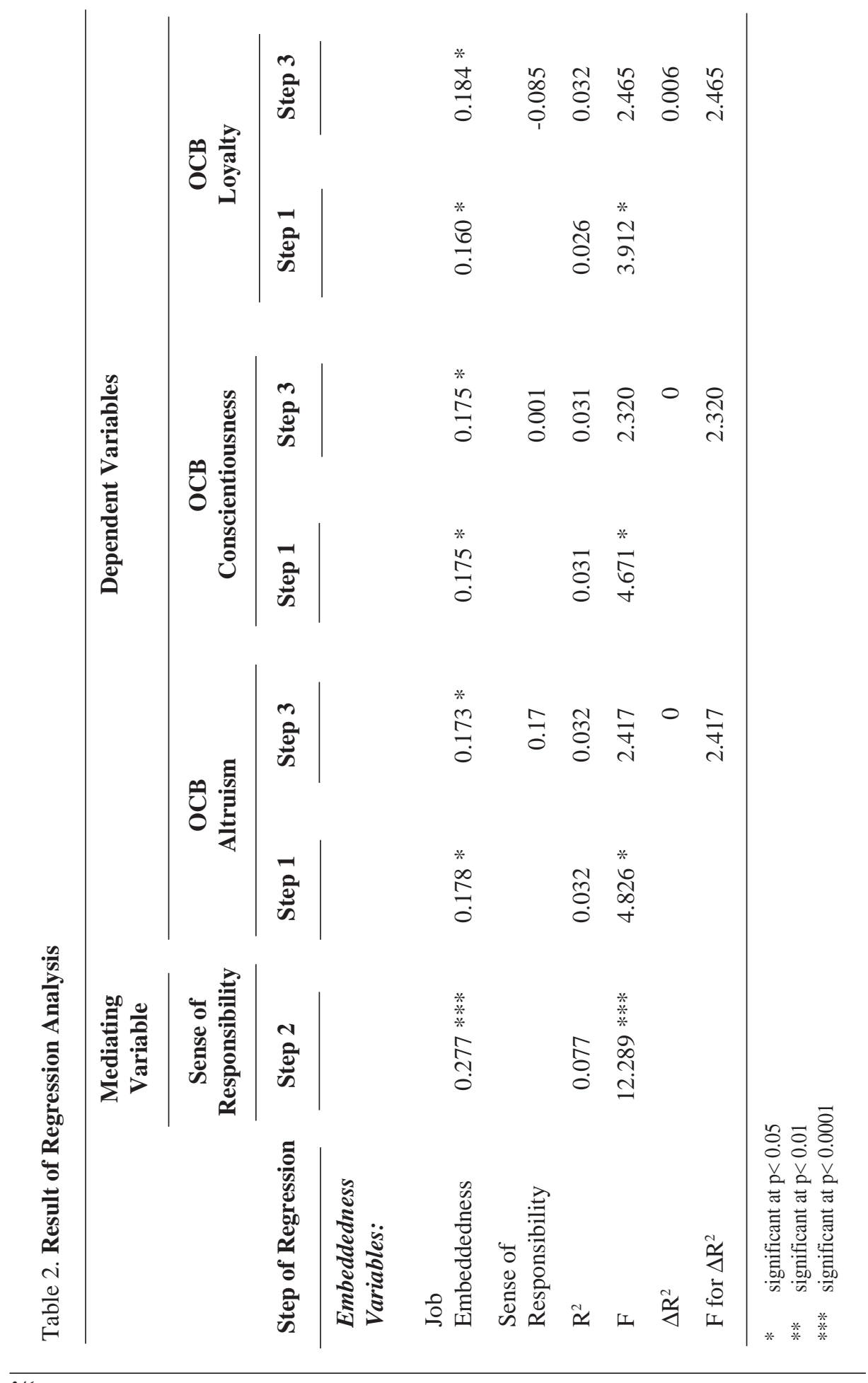


Wijayanto \& Kismono - The Effect of Job Embeddedness on Organizational Citizenship Behavior

tiousness: mean $=5.9867$, s.d. $=0.74624$;

loyalty: mean $=5.7833$, s.d. $=0.72449$ ).

The Pearson product moment correlation in Table 1 indicated that embeddedness from off-the-job factors (JEC) positively correlated with sense of responsibility $(\mathrm{r}=0.236, \mathrm{p}<0.01)$ but weakly correlated with OCB dimensions (altruism: $\mathrm{r}=$ 0.087 , n.s.; conscientiousness: $r=0.124$, n.s; and loyalty: $r=0.098$, n.s). On the contrary, embeddedness resulting from forces from on-the-job factors (JEO) correlated positively with sense of responsibility $(\mathrm{r}=0.226, \mathrm{p}<0.01)$ and OCB dimensions (altruism: $\mathrm{r}=0.226, \mathrm{p}<0.05$; conscientiousness: $\mathrm{r}=0.174, \mathrm{p}<0.05$; and loyalty: $r=0.180, p<0.05)$.

Hypothesis 1 posits that there will be a positive correlation between job embeddedness and OCB. Results of Pearson product moment correlation in Table 1 show that job embeddedness correlates positively and significantly with OCB (altruism: $r=0.178, p<0.05$; conscientiousness: $\mathrm{r}=0.175, \mathrm{p}<0.05$; and loyalty: $r=0.160, p<0.05)$.

Hypothesis 2 posits that employee's sense of responsibility toward organization will mediate the effect of job embeddedness on OCB. MacKinnon (1994) as well as Baron and Kenny (1986) in Kenny (2003) suggested that mediation effect occurs when:

(1) independent variable has significant effect on dependent variable;

(2) independent variable has significant effect on mediating variable;

(3) mediating variable has significant effect on dependent variable when the dependent variable is regressed on both independent and mediating variable;

(4) the effect of independent variable on dependent variable in third equation must be smaller than the effect of independent variable on dependent vari- able in first equation (the calculation of effects in both step 3 and 4 are estimated in the same regression equation).

Table 2 presents the result of mediated regression analysis on each dimension of OCB.

From Table 2, it can be shown that job embeddedness has a significant effect on each dimension of OCB (first step is fulfilled) (altruism: $b=0.178, r<0.05$; conscientiousness: $b=0.175, r<0.05$; loyalty $b=0.160, r<0.05)$. In addition, job embeddedness also has a significant effect on sense of responsibility (step 2 is fulfilled) $(b=0.277, r<0.001)$. However, when OCB is regressed on both independent and mediating variable, sense of responsibility has no significant effect on each dimension of OCB (altruism: $b=0.17$, n.s; conscientiousness: $b=0.001$, n.s; loyalty $b=-0.085$, n.s.), and job embeddedness is the only variable which has a significant effect on OCB (altruism: $b=0.173, r<$ 0.05 ; conscientiousness: $b=0.175, r<0.05$; loyalty: $b=0.184, r<0.05)$. We also found that there are no apparent differences between the regression coefficients for effect of job embeddedness on OCB in the third step and the regression coefficient in the first step of mediated regression analysis. Thus, hypothesis 2 is not supported.

\section{Discussion and Implication}

This paper presents preliminary evidence concerning the relationship between job embeddedness and OCB. From the correlation analysis presented in the previous section, it can be shown that job embeddedness is positively related to employee's OCB. This result is consistent with previous research on the relationship between positive attitude toward organization and employee's active involvement 
in OCB (Bateman and Organ 1983; Smith et al. 1983; Puffer 1987; Organ and Konovsky 1989; Williams and Anderson 1991; Bolon 1997; Netemeyer et al. 1997, O'Reilly and Chatman 1986; Becker 1992; Hunt and Morgan 1994; Shore and Wayne 1993; Cardona and Espejo 2002; Schappe 1998). In addition, because job embeddedness consists of dimensions that are less affective in nature (Mitchell et al. 2001), the result of first hypothesis in the current study is consistent with previous research on positive relationship between non-affective aspect of employee attitude and OCB (Organ and Konovsky 1989; Williams and Anderson 1991). This result also supports Mitchell et al. (2001) notion that there is positive relationship between employee embeddedness and their active involvement in OCB.

However, this study failed to support the prediction that sense of responsibility will mediate the causal relationship between job embeddedness and OCB. There are several possible explanations with regard to this result.

Morrison and Phelps (1999) in their research on a form of extra role behavior; i.e. taking charge, suggested that some mediating mechanisms exist between employee's sense of responsibility and their actual involvement in taking charge behavior, in the form of judgment about the likely outcomes (cost and benefit) and the likely success of such behavior. This judgment might affect employee's valence, which in turn also might affect employee's actual involvement in taking charge (Graham 1986 in Morrison and Phelps 1999). The same mechanism may also occur in this study, that is, although the respondents may have feeling of responsibility to help their institution, they are less motivated to be involved in OCB perhaps because previous experiences showed that respondent's involvement in such behavior did not correspond with the outcomes they expected.

Another possibility is that perhaps the cognitive aspects of respondents play an important role in shaping their decision to involve in OCB. Pearce and Gregersen (1991) suggested that sense of responsibility was asymmetric in nature, which is based on individuals' concern to help, and not because they expected some reciprocity from the recipients. This indicates that sense of responsibility occurs because of one's empathy to others, which in this study is his or her employing organization. This is also an indication that sense of responsibility is affected more by individual's affective aspects. We predict that in this study the affective side of sense of responsibility is less likely to occur, and that respondents' involvement in OCB are influenced more by their cognition or considered evaluation and judgment about aspects of work situation [Organ and Near (1985) in Lee and Allen (2002); Organ and Konovsky (1989)] than by their empathy to help. The characteristic of job embeddedness itself, that is less affective in nature, might also play an important role in shaping respondent's cognitive feeling of responsibility. Because nurses embeddedness is shaped by less affective reasons, then it may be that their feeling of responsibility is also less affective, and influenced by cognition that involved respondents' evaluation about external circumstances. This cognition might affect their decision to involve in OCB. However, because we did not include all possible variables that may influence the decision made by embedded and responsible employee to be involved in $\mathrm{OCB}$, then it may be that the unavailability of those variables cause an insignificant relation between sense of responsibility and OCB. 
Wijayanto \& Kismono - The Effect of Job Embeddedness on Organizational Citizenship Behavior

Based on the above possibilities, we predict that there are other variables reflecting employee's judgment of external circumstances which might influence the relationship between sense of responsibility and OCB, but are not included in this study. It means, perhaps, the relationship between job embeddedness, sense of responsibility, and OCB is more complex. The possibility of other potential variables which need to be included in our study, are also indicated by the result in our first step of regression analysis. It has been shown that job embeddedness has a significant direct effect on OCB in the first regression, however its ability to explain the variance on each dimension of OCB is very small (altruism: adj. $R^{2}=0.032, F$ test 4.826*; conscientiousness: adj. $\mathrm{R}^{2}=0.031$, F test $4.671^{*}$; loyalty: adj. $\mathrm{R}^{2}=0.026, \mathrm{~F}$ test $3.912 *)$. This would be an indication for the need of including other variables in future research.

The result of regression analysis in this study may also be considered as inconsistent with previous researches that found a positive relationship between sense of responsibility and forms of extra role behavior (Morrison and Phelps 1999; DePasquale 1999; Pearce and Gregersen 1991). However, the current study uses a different conceptualization of sense of responsibility and tests it against extra role behavior (OCB) which has a slight difference from other extra role activities used in previous studies (Morrison and Phelps 1999; DePasquale 1999).

With regard to Pearce and Gregersen (1991) study, we adopted their conceptualization about sense of responsibility. However, in their research, Pearce and Gregersen (1991) defined sense of responsibility as asymmetric concern to co-worker and used Hackman and Oldham (1975) instruments as proxy of sense of responsibility to other individuals. Here in this study, we define sense of responsibility as asymmetric concern to organization and used the Hackman and Oldham (1975) as proxy of such concern to organization. Besides, Pearce and Gregersen (1975) measured only one form of $\mathrm{OCB}$; which is altruistic behavior. In our study, however, we took a broader form of citizenship behavior, which involved not only behavior to other individuals, but also behaviors targeted at organization. Ourinconsistency with Pearce and Gregersen (1991) study is perhaps because the instruments we used in this study are unable to capture the phenomenon of OCB. This is shown by the weak correlation between sense of responsibility and all forms of $\mathrm{OCB}$ (Table 1). Future research should use a different and better conceptualization of sense of responsibility in order to capture all forms of $\mathrm{OCB}$, and also the phenomenon on both job embeddedness and OCB.

As mentioned previously, the current study presents preliminary evidence concerning the relationship between job embeddedness and OCB. Based on the current results, we recommend future research to test the relationship between job embeddedness and OCB more comprehensively. We suggest the need of including other variables that may have impact on this relationship, and also using more appropriate conceptualization of sense of responsibility in order to capture phenomenon in both OCB and job embeddedness.

The current study has some implications for organization as well as for managers. Based on our correlation analysis results, we recommend the need for managers to pay attention to, and to increase

* significant at $\rho<0.05$ 
employee perceptions of embeddedness by providing support, not only to on-thejob activities but also off-the-job activities as well. The need to pay attention to issues of employee's embeddedness is also supported by Mitchell et al. (2001) and Pracimasanti (2004) findings on the effect of job embeddedness in reducing employee's intention turnover.

Another implication is on OCB issues. This study tested two multidimensional construct with different characteristic; i.e. job embeddedness and OCB. The regression analysis results indicate that OCB is better conceptualized as latent multidimensional construct. This result is in line with LePine et al. (2002) and also Cardona and Espejo's (2002) suggestions.

\section{Limitation}

As previously mentioned in the discussion section, our model on the role of sense of responsibility in mediating the effect of job embeddedness on OCB is probably not comprehensive enough to capture all phenomena surrounding the variables examined in this current study. Because job embeddedness is relatively new construct and literatures about it is relatively very few, especially with regard to its relationship with $\mathrm{OCB}$, we begin this study by exploring the possible subsequent variables that might influence the relationship between job embeddedness and OCB. Sense of responsibility, as a form of employee's concern toward organization, is believed to be an appropriate variable that would become subsequent consequence of being embedded in organization, which in turn becomes employee's OCB motivator. However, contrary to our expectation, the result fails to support as OCB predictor. It may be because there are other variables, e.g. mediating variables reflecting judgment related to outcomes from employee's involvement in extra role activities in relation between sense of responsibility and OCB as predicted by Morrison and Phelps (1999), which are not included in our study. Another possibility is perhaps that the sense of responsibility toward organization developing from employee embeddedness, which is less affective in nature, is influenced more by respondent cognitive aspects than their affective aspects. These warrant the need to consider other variables related to employee's judgment of their work situation that they consider when making a decision to be involved in OCB in future studies on the relationship between job embeddedness, sense of responsibility, and OCB.

With regard to the respondents, the generalization of the current result of the current study needs to be considered carefully, because we tested the prediction only on homogenous samples (i.e. nurses). Future research should test prediction with regard to the relationship between job embeddedness and OCB with more diverse samples.

Another limitation related to respondents in the current study is that although we were trying to minimize common methods bias resulting from the use of selfreport methods by using supervisory-rated OCB, there are possibilities that the use of supervisor could also make our result bias. The first is concerning impression management (Bolino 1999). Impression management is a process by which an individual attempt to influence the image others have toward him or her. Bolino (1999) suggested that some forms of employees' voluntary behavior are actually image enhancing activities, and this type of behavior is often exhibited in front of superior with the purpose of enhancing superior's evaluation about them. Another possibility is based on whether supervisors and 
Wijayanto \& Kismono - The Effect of Job Embeddedness on Organizational Citizenship Behavior

employees have different perception with regard to OCB-like behaviors. Morrison (1994) found that supervisors have different perception from their employees in defining OCB-like behaviors as in-role or extra role. The implication of her finding for this study is if supervisors and their subordinates did not have consensus with regard to OCB like behavior, then there is an ambiguity regarding whether employees' OCB as reported by their supervisors is actually the employee's extra role or part of the employee's in-role performance.
Another limitation of the current study is concerning scoring procedure. Some items in links to community dimensions are dichotomous and some items in link to organization are in ratio scale. We have to standardize those items first, following Mitchell et al. (2001) by using Z score in order to enable us to conduct further analyses. However, this process might have impact on low reliability for those dimensions as reported in this study and also might reduce meaning of responses, especially on items that are dichotomous.

\section{References}

Ackfeldt, A. L., and L. V. Coote. 2000. An investigation into the antecedents of organizational citizenship behaviors. Paper for ANZMAC 2000 Visionary Marketing for the $21^{\text {st }}$ century: Facing the challenge (internet).

Baron, R. M., and Kenny, D. A. 1986. The moderator-mediator distinction in social psycological research: Conceptual, strategic, and statistical considerations. Journal of Personality and Social Psychology 51: 1173-1182.

Bateman, T. S., and D. W. Organ. 1983. Job satisfaction and the good soldier: The relationship between affect and employee citizenship. Academy of Management Journal 26: 587-595.

Becker, T. E. 1992. Foci and bases of commitment: Are they distinctions worth making? Academy of Management Journal 35: 232-244.

Bolino, M. C. 1999. Citizenship and impression management: A good soldiers or good actors? Academy of Management Review 24: 82-89.

Bolino, M. C., W. H. Turnley, and J. M. Bloodgood. 2002. Citizenship and the creation of social capital in organizations. Academy of Management Review 27: 505-522.

Bollen, K., and R. Lennox. 1991. Conventional wisdom on measurement: A structural equation perspective. Psychological Bulletin 110: 305-314.

Bolon, D. S. 1997. Organizational citizenship behavior among hospital employees: A multidimensional analysis involving job satisfaction and organizational commitment. Hospital and Health Service Administration 42: 221-241.

Cardona, P., B. S. Lawrence, and P. M. Bentler. 2003. The influence of social and work exchange relationships on organizational citizenship behavior. Working Paper at IESE Business School-University of Navarra (Retrieved from www.iese.edu/research/pdfs/DI-0495-E.pdf). 
Cardona, P., and A. Espejo. 2002. The effect of rating source in organizational citizenship behavior: A multitrait-multimethod analysis. Research Paper at IESE Business School-University of Navarra (Retrieved from www.iese.edu/research/pdfs/DI0474.pdf).

Chin, W. W. 1998. Issues and opinion on structural equation modelling. Management Information Systems Quarterly 22.

DePasquale, J. P. 1999. Exploring personal responsibility for participation in organizational process: Antecedents and consequences. Dissertation submitted to the Faculty of Virginia Polytechnic Institute and State University (internet).

Frese, M., W. Kring, A. Soose, and J. Zempel. 1996. Personal initiative at work: Differences between east and West Germany. Academy of Management Journal 39: 37-63.

George, J. M. 1991. State or trait:Effects of positive mood on prosocial behaviors at work. Journal of Applied Psychology 76: 299-307.

Greenberg, J., and R. A. Baron. 2000. Behavior in Organizations: Understanding and Managing the Human Side of Work. Prentice Hall, Inc.

Hair Jr., J. F., R. E. Anderson, R. L. Tatham, and W. C. Black. 1998. Multivariate Data Analysis. Prentice-Hall International, Inc.

Hunt, S. D., and R. M Morgan. 1994. Organizational commitment: one of many commitments or key mediating construct. Academy of Management Journal 37: 1568-1587.

Kenny, D.A. 2003.Mediation. Retrieved from http://users.rcn.com/dakenny/mediate.htm

Konovsky, M. A., and D. W. Organ. 1996. Dispositional and contextual determinants of organizational citizenship behavior. Journal of Organizational Behavior 17: 253266.

Konovsky, M. A., and S. D. Pugh. 1994. Citizenship behavior and social exchange. Academy of Management Journal 1994: 656-669.

Kristof, A. L. (1996). Person-organization fit: An integrative review of its conceptualizations, measurements, and implications. Personnel Psychology 49: 149.

Law, K. S., C. Wong, and W. H. Mobley. 1998. Toward taxonomy of multidimensional construct. Academy of Management Journal 23: 741-755.

Lee, K., and N. J. Allen. 2002. Organizational citizenship behavior and workplace deviance: The role of affect and cognition. Journal of Applied Psychology 87: 131142.

LePine, J. A., A. Erez, and D. E. Johnson. 2002. The nature and dimensionality of organizational citizenship behavior: A critical review and meta analysis. Journal of Applied Psychology 87: 52-65.

MacKinnon, D. P. 1994. Mediation FAQ. www.public.asu/ davidpm/ripl/q\&a.htm 
Wijayanto \& Kismono - The Effect of Job Embeddedness on Organizational Citizenship Behavior

Meyer, J. P., N. J. Allen, and C. A. Smith. 1993. Commitment to organizations and occupations: Extension and test of a three component conseptualization. Journal of Applied Psychology 78: 538-551.

Mitchell, T. R., B. C. Holtom, T. W. Lee, C. J. Sablynski, and M. Erez. 2001. Why people stay: Using job embeddedness to predict voluntary turnover. Academy of Management Journal 44: 1102-1121.

Moorman, R. H., G. L. Blakely, and B. P. Niehoff. 1998. Does perceived organizational support mediate the relationship between procedural justice and organizational citizenship behavior? Academy of Management Journal 41: 351-357.

Morrison, E. W. 1994. Role definitions and organizational citizenship behavior: The importance of understanding the employee perspective. Academy of Management Journal 37: 1543-1567.

Morrison, E. W., and C. C. Phelps. 1999. Taking charge at work: Extra role effort to initiate workplace change. Academy of Management Journal 42: 403-419.

Motowidlo, S. J., and J. R. Van Scooter. 1994. Evidence that task performance should be distinguished from contextual performance. Journal of Applied Psychology 79: 475480 .

Netemeyer, R. G., J. S. Boles, D. O. McKee, and R. McMurrian. 1997. An investigation into the antecedents of organizational citizenship behaviors in a personal selling context. Journal of Marketing 61: 85-98.

O’Reilly, C., and J. Chatman. 1986. Organizational commitment and psychological attachment: The effects of compliance, identification, and internalization on prosocial behavior. Journal of Applied Psychology 71: 492-499.

Organ, D. W., and K. Ryan. 1995. A meta analytic review of attitudinal and dispositional predictors of organizational citizenship behavior. Personnel Psychology 48: 775802.

Organ, D.W., and M. Konovsky. 1989. Cognitive versus affective determinants of organizational citizenship behavior. Journal of Applied Psychology 74: 157-164.

Pearce, J. L., and H. B. Gregersen 1991. Task interdependence and extra role behavior: A test of mediating effect of felt responsibility. Journal of Applied Psychology 76: 838-844.

Podsakoff, P. M., and S. B. MacKenzie 1994. Organizational citizenship behavior and sales unit effectiveness. Journal of Marketing Research 31: 351-363.

Podsakoff, P. M., S. B. MacKenzie, and W. H. Bommer 1996. Meta analysis of the relationships between Kerr and Jermier's substitutes for leadership and employee job attitudes, role perceptions, and performance. Journal of Applied Psychology 81: 380399.

Pracimasanti, B. 2004. Analisis pengaruh dimensi-dimensi job embeddedness terhadap turnover intention karyawan. Thesis. Faculty of Economics, Gadjah Mada University. 
Puffer, S. M. 1987. Prosocial behavior, non compliant behavior, and work performance among commission salespeople. Journal of Applied Psychology 72: 615-621.

Robinson, S. L., and E. W. Morrison. 1995. Psychological contract and OCB: The effect of unfulfilled obligations on civic virtue behavior. Journal of Organizational Behavior 16: 289-298.

Schappe, S. P. 1998. The influence of job satisfaction, organizational commitment, and fairness perceptions on organizational citizenship behavior. The Journal of Psychology 132: 277-290.

Seetton, R. P., N. Bennett, and S. C. Liden 1996. Social exchange in organizations: perceived organizational support, leader member exchange, and employee reciprocity. Journal of Applied Psychology 81: 219-227.

Shepard, J. M., M. Betz, and L. O. O'Connell. 1997. The proactive corporation: Its nature and causes. Journal of Business Ethics 16: 1001-1010.

Shin, D. H., Yusof, and M.Venkatesh. 2002. Community Network and Social Embeddedness: Survey and Result. Retrieved from www.tprc.org/papers/2002/73/ tpre_final.pdf.

Shore, L. M., and S. J. Wayne 1993. Commitment and employee behavior: Comparison of affective commitment and continuance commitment with perceived organizational support. Journal of Applied Psychology 78: 774-780.

Smith, C. A., D. W. Organ, and J. P. Near. 1983. Organizational citizenship behavior: Its nature and antecedents. Journal of Applied Psychology 68: 653-663.

Uzzi, B. 1997. Social structure and competition in interfirm networks: the paradox of embeddedness. Administrative Science Quarterly 42: 35-67.

Van Dyne, L., J. W. Graham, and R. M. Dienesch. 1994. Organizational citizenship behavior: Construct redefinition, measurement, and validation. Academy of Management Journal 37: 765-802.

Van Scooter, J. R, and S. J. Motowidlo. 1994. Evidence for two factors of contextual performance: Job dedication and interpersonal facilitation. Journal of Applied Psychology 81: 525-531.

Vaske, J. J., and K. C. Kobrin. 2001. Place attachment and environmentally responsible behavior. The Journal of Environmental Education 32: 16-21.

Wayne, S. J., L. M. Shore, W. H. Bommer, and L. E. Tetrick. 2002. The role of fair treatment and rewards in perceptions of organizational support and leader member exchange. Journal of Applied Psychology 87: $590 ? 598$.

Williams, L. J., and S. E. Anderson. 1991. Job satisfaction and organizational commitment as predictors of organizational citizenship and in-role behavior. Journal of Management 17: 601-617. 